\title{
Unusual Complications Related to Endoscopic Retrograde Cholangiopancreatography and Its Endoscopic Treatment
}

\author{
Chang-II Kwon, Sang Hee Song, Ki Baik Hahm and Kwang Hyun Ko \\ Digestive Disease Center, CHA Bundang Medical Center, CHA University, Seongnam, Korea
}

\begin{abstract}
Endoscopic retrograde cholangiopancreatography (ERCP)-induced complications, once occurred, can lead to significant morbidity. Commonly $5 \%$ to $10 \%$ of patients experience procedure related complications such as post-ERCP pancreatitis, biliary hemorrhage, and cholangitis, in descending order. However, complications such as perforation, pneumothorax, air embolism, splenic injury, and basket impaction are rare but are associated with high mortality if occurred. Such unexpected unusual complications might extend the length of hospitalization, require urgent surgical intervention, and put the patient in miserable condition leading to permanent disability or mortality. Although these ERCP-induced complications can be minimized by a skilled operator using advanced techniques and devices, the occurrence of unusual complications are hard to expect and induce very difficult management condition. In this review, we will focus on the uncommon complications related to ERCP. This review is also aimed at suggesting optimal endoscopic treatment strategies for several complications based on our institutional experiences.
\end{abstract}

Key Words: Cholangiopancreatography, endoscopic retrograde; Complication; Endoscopy

\section{INTRODUCTION}

Since Endoscopic retrograde cholangiopancreatography (ERCP)-induced complications are associated with significant morbidity and occasional mortality in patients, endoscopists have troublesome anxiety as well as panic. Simply, the best way to prevent such complications might be to avoid performing ERCP, but not in reality. It is most important, therefore, to consider indications and risk/benefit ratio thoroughly before ERCP. Physicians need to evaluate and determine "If ERCP is really necessary for the patient, and if there are other modalities such as safer method of diagnosis or treatment." If ERCP is an inevitable condition to do, an experienced and skillful endoscopist should perform according to a safe and step-wise procedure. $^{1-3}$

The reported incidences of overall short-term complications

Received: March 21, 2013 Revised: April 1, 2013

Accepted: April 1, 2013

Correspondence: Kwang Hyun Ko

Digestive Disease Center, CHA Bundang Medical Center, CHA University, 59 Yatap-ro, Bundang-gu, Seongnam 463-712, Korea

Tel: +82-31-780-5220, Fax: +82-31-780-5219, E-mail: bluehipp@cha.ac.kr

(c) This is an Open Access article distributed under the terms of the Creative Commons Attribution Non-Commercial License (http://creativecommons.org/ licenses/by-nc/3.0) which permits unrestricted non-commercial use, distribution, and reproduction in any medium, provided the original work is properly cited. are approximately from $5 \%$ to $10 \%$ according to various prospective studies, though the data might be slightly different depending on the definition of ERCP-induced complication and the method of data collection. For instance, post-ERCP pancreatitis is reported to occur in more than $20 \%$, among which $5 \%$ are in condition of severe complications, in which the sphincter of Oddi (SOD) dysfunction is usually regarded as a high risk group. Though ERCP-related death is reported to be very rare, it could occur in less than $0.5 \%{ }^{4}$

ERCP-induced complications occur in various categories, including the most common post-ERCP pancreatitis, and less common hemorrhage and cholangitis. Unusual complications such as perforation, pneumothorax, air embolism, splenic injury, and basket impaction are rare but risky, once developed. Several reports consistently concluded that typical and common ERCP-induced pancreatitis can be minimized when performed by a skilled operator using advanced techniques and devices. However, the occurrence of unusual complications are hard to expect and difficult to manage. Such unusual complications extend the length of hospitalization, may require surgical intervention and may cause permanent disability, or even death, if not managed properly. Any endoscopists who perform ERCP will agree that they sometimes experience fear and challenge in such situations. 
In this review, we will focus on the uncommon complications related to ERCP other than usual complications which have been already highlighted by many endoscopists. This review is also aimed at suggesting optimal endoscopic treatment strategies for several complications based on our institutional experiences.

\section{PERFORATION}

One of the most feared complications might be perforation. Though ERCP-related perforation has been reported in less than $1 \%$, mostly in association with sphincterotomy, ${ }^{2,4}$ perforation needs to be diagnosed immediately and should be treated promptly, since delayed diagnosis and intervention of perforation may lead to the development of sepsis and multiorgan failure, which are the causes of higher mortality ( $8 \%$ to $23 \%){ }^{5}$ The most commonly used classification of ERCP-induced perforation is the one suggested by Stapfer et al., ${ }^{6}$ which is set up based on its mechanism and can predict the need for surgery depending on the anatomic location and severity of injury. According to this classification, ERCP-induced perforation can be categorized into four types (Table 1, Fig. 1). Risk factors associated with perforation are not clearly identified due to the low incidence. However, the incidence of bowel perforation is more frequent in patients who received Billoth II gastrectomy or roux-en-Y operation, while sphincterotomy perforation is more common during precut method with a needle knife or in patients suspected of SOD dysfunction. ${ }^{1}$ Usual conservative medical managment requires nasobiliary drain to avoid bile spillage, with nasogastric tube draining to prevent infiltration of intestinal contents into the retroduodenal space. These treatments should be accompanied by intravenous antibiotics, strict fasting, and surgical consultation as well. ${ }^{2}$ The treatment of post-ERCP perforation should be determined based on the type and severity of the leak and clinical manifestations. For type I and type II perforations, surgical treatment is generally recommended, although recent development of endoscopic treatments enabled successful treatment with endoscopic clippings, endoloop applications, and endoscopic closure devices (Figs. 2-4). Guide-wire or stent- related extramural perforations can be treated easily with endoscopic treatment using adequate ductal drainage above the leak site. ${ }^{7-9}$ Sphincterotomy-related perforation, unlike other types of perforations, can be fully prevented. Limiting the length of cutting wire for sphincterotome that touches the tissues or using stepwise incisions is a safer way of preventing perforations. If perforation is suspected during sphincterotomy, extraluminal leakage can be identified by injecting a small amount contrast while passing the inserted catheter or papillotome by the suspected site of perforation following the guide-wire under the fluoroscopic guidance. Identified perforation, regardless of its type, should be confirmed for any presence of contrast leakage and retroperitoneal or intraperitoneal air with abdominal computed tomography (CT). Care should be taken, however, to make a decision based on the patient's clinical condition, since $29 \%$ of asymptomatic patients have free retroperitoneal air observed at the CT images taken within 24 hours after ERCP, which is not associated with the severity of the complication or the need for sugery. ${ }^{10} \mathrm{Im}$ mediate closing with endoscopic clipping may be attempted for perforation sites with confirmed leakage., ${ }^{9,11}$ However, since clipping with a side-view duodenoscopy can be technically difficult, a cap-assisted, forward-view endoscopy may be applied. Other treatments of perforation after biliary sphincter-

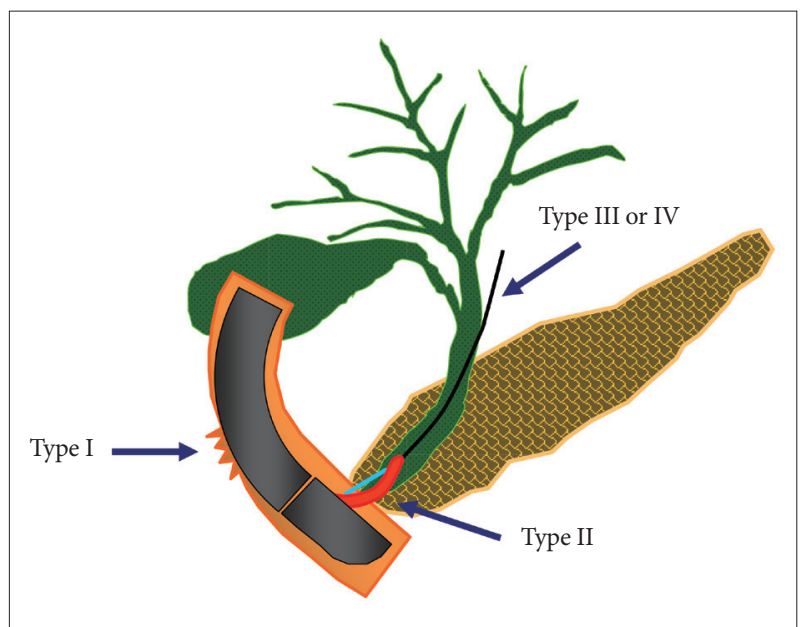

Fig. 1. The illustration of the classification of endoscopic retrograde cholangiopancreatography-related perforations.

Table 1. Classification of Endoscopic Retrograde Cholangiography-Related Perforations ${ }^{6}$

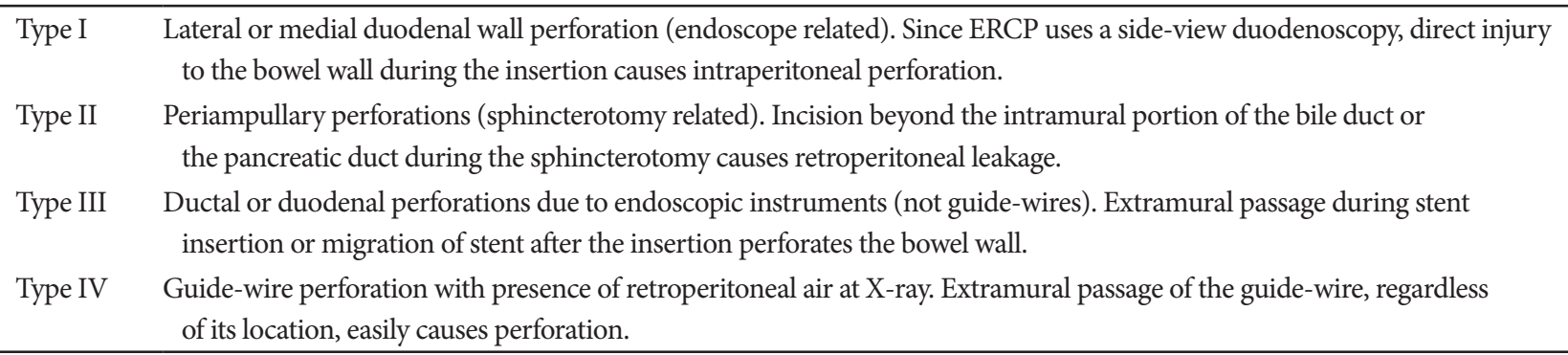



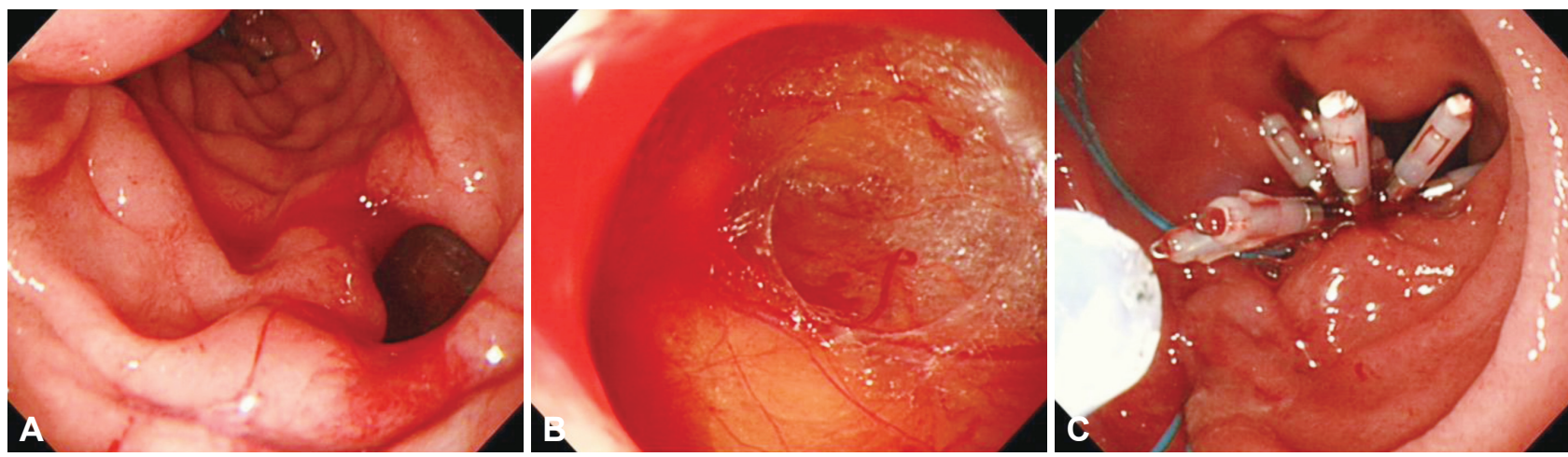

Fig. 2. Endoscopic images of a case with type I perforation. (A) A large perforation on lateral duodenal wall. (B) Duodenal serosa and omentum is revealed. (C) Successful primary endoscopic closure using multiple clips and endoloop.
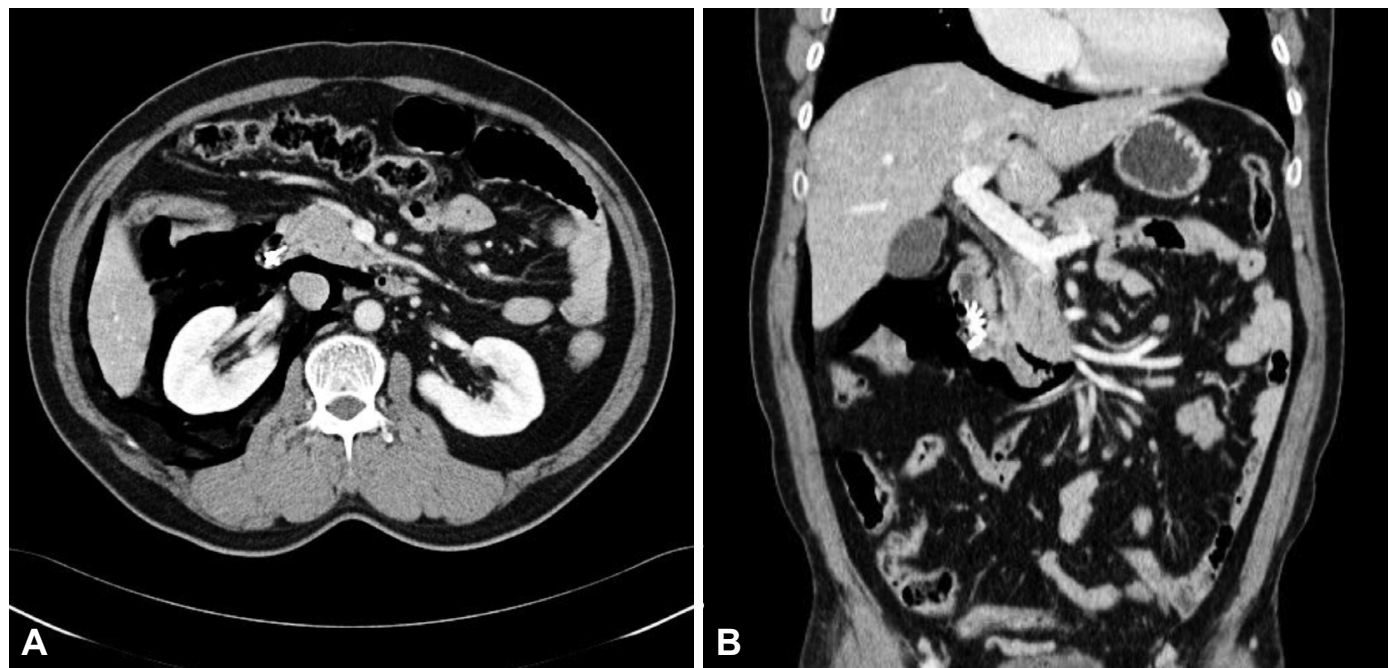

Fig. 3. (A, B) Abdominal computed tomography of a case with successful primary endoscopic closure for type I perforation. It shows a pneumoretroperitoneum at the right side abdomen, due to perforation at the second portion of the duodenum. Free airs are revealed at the right perirenal, anterior pararenal and posterior pararenal spaces. Several clips are noted at the second portion of the duodenum without visible definite defect and soiling or fluid collection at the periduodenal area.

otomy include the insertion of a fully covered self-expandable metal stent. ${ }^{12-14}$ Asymptomatic patients with only the evidence of free air can normally be improved with a conservative management consisting of bowel rest and antibiotics. Inappropriate biliary drainage may cause the infiltration of bile or fluid leakage into the perforated site, increasing the morbidity. 6.8 Patients whose leakage volume is enough to be observed on $\mathrm{CT}$, those with confirmed continous leakage, or whose clinical condition is deteriorating should be considered for immediate surgical approach. Since mortality due to sepsis is as high as 50\% among patients with failure of conservative medical managment, surgical managmenet should not be hesitated in such patients. ${ }^{2,6}$ Type I and type III duodenal perforations due to endoscope tip or stent migration might be treated with endoscopic clipping. ${ }^{15-17}$ However, most cases of duodenoscopyinduced duodenal perforation cannot be closed with clipping only, due to the wide range of perforation. Combination of endoscopic clipping and endoloop application has been intro- duced to avoid operation. Since the initial report by Endo et al., ${ }^{18}$ there have been various clinical trials concerning the usage of an endoloop and multiple hemoclips to cover large mucosal defects following endoscopic submucosal dissection and endoscopic mucosal resection. ${ }^{19,20}$ When perforation is suspected, relatively thin forward viewing one-channel endoscope with a cap on the tip of the endoscope (transparent capassisted) may as well be used for observation, while minimizing air insufflation or using $\mathrm{CO}_{2}$ generator. The reason for choosing a one-channel endoscope, instead of a two-channel endoscope, is that a one-channel endoscope allows separating two catheters and it can provide a wide range of therapeutic activities during therapy. When using a two-channel endoscope, although simultaneous insertion of one catheter with an endoloop and the other catheter with a clip into each channel can fix the clips together with the endoloop, technical problems can occur in cases with a lesion difficult to access or with a narrow lumen, due to the wider diameter of the two- 

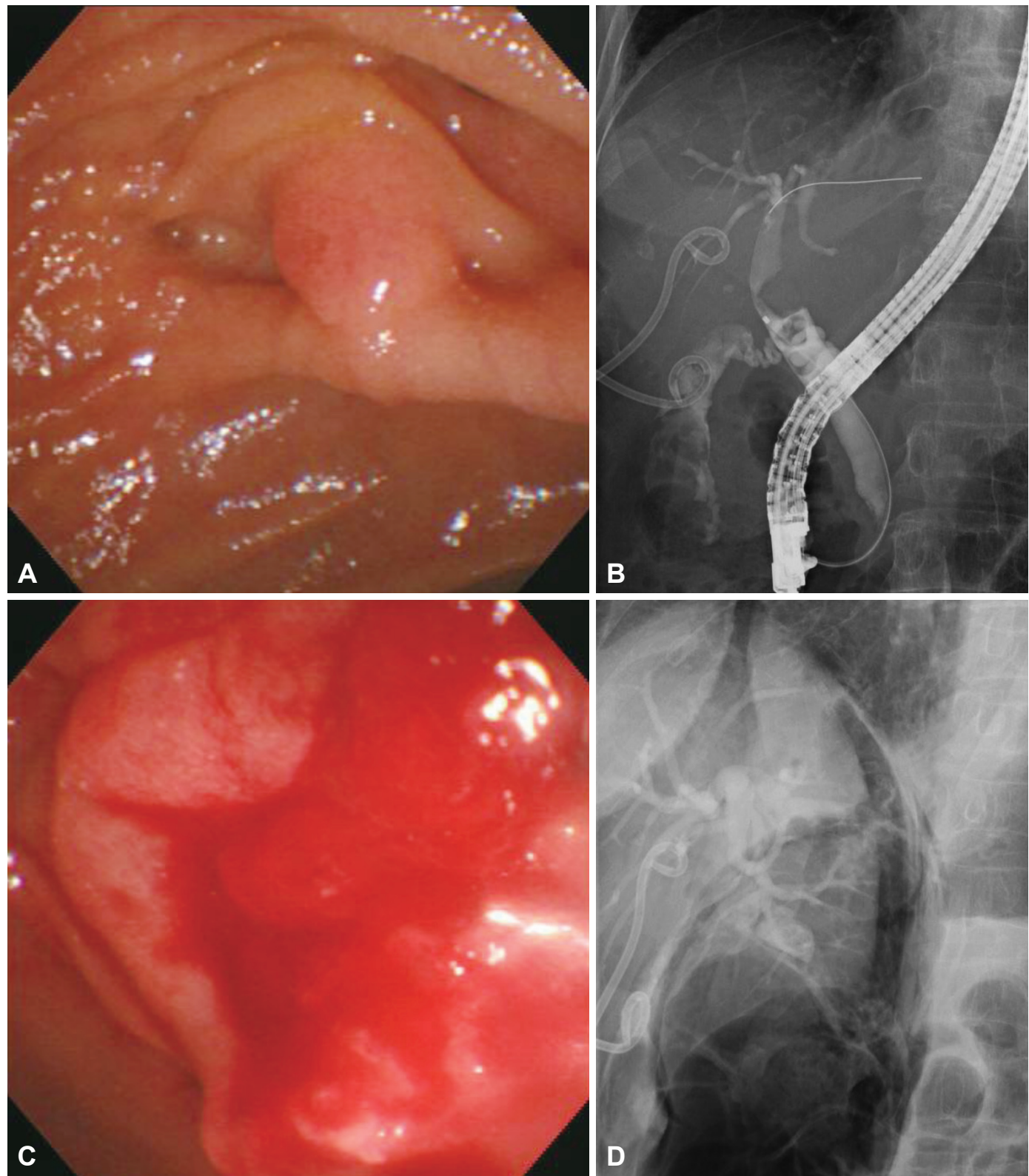

Fig. 4. Endoscopic images and cholangiograms of a case with type II perforation. (A) Endoscopic view of ampulla. (B) Cholangiogram shows mild biliary dilatation with several round filling defecs in the common bile duct. (C) Endoscopic view shows active bleeding and edematous change at the postsphincterotomy's area. (D) Cholangiogram shows unsuspected large amount of air in the retroperitoneal area.

channel endoscope and the parallel existence of two-working channels. The combination therapy is conducted as follows (Figs. 5-7). Before insertion of cap-assisted endoscope, an alligator forceps are inserted into the working channel of the endoscope and the alligator forceps caught the tip of an endoloop. Then, the endoloop containing the catheter and endoscope are inserted into the patient. At placement of them around the perforated area, the alligator forceps are opened for detaching the endoloop containing the catheter. Then, the endoloop containing the catheter is properly released. After insertion of the clipping catheter, the tip of the endoloop is caught with the clip and clipping is started from the distal margin.
Thereafter, multiple clips are attached with the endoloop to the perforated area and vice versa (a bunch-like clip formation is caught and fixed with the endoloop). Finally, the endoloop is tightened and this closes the perforated area. ${ }^{21}$ Change of the patient's condition should be monitored while performing conservative managements such as antibiotics, total parenteral nutrition and nasogastric tube drainage. If the clinical symptoms have not been deteriorated, upper gastrointestinal investigations using gastrograffin should be performed, following approximately 1 -week period of conservative management, to ascertain whether extra-duodenal spillage is present. 


\section{PNEUMOTHORAX}

ERCP-induced retroperitoneal perforation may develop to pneumothorax, which is a very rare but unpredictable and potentially life-threatening complication. This complication

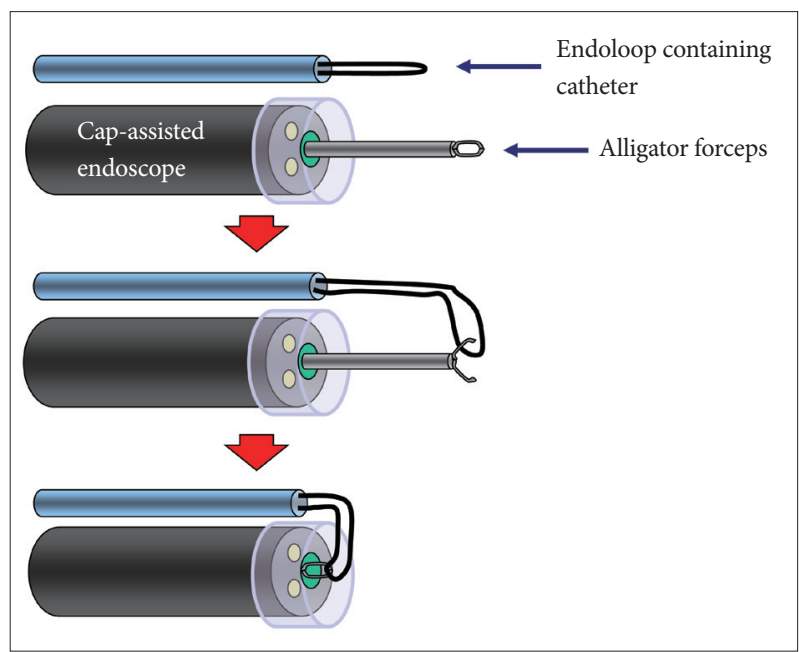

Fig. 5. Illustration of cap-assisted endoscope and instruments before endoscopic combination therapy. An alligator forceps are inserted into the working channel of the endoscope and the alligator forceps caught the tip of an endoloop. occurs regardless of age, mostly on the right side, despite the appearance of bilateral development, and accompanies retroperitoneal, mediastinal and subcutaneous emphysema. ${ }^{22}$ As mentioned earlier, the main risk factor is sphincterotomy, which is associated with retroperitoneal perforation. Pneumothorax is not an indication of surgical intervention. The reported prognosis of pneumothorax has been acceptable after conservative managements consisting of the administration of oxygen, chest tube insertion, broad-spectrum antibiotics, and total parenteral nutrition, although the prognosis will vary depending on the progress of the retroperitoneal perforation. ${ }^{23}$

\section{HEPATIC HEMATOMA}

Hepatic hematoma is a very rare complication of ERCP. The suggested mechanism is an injury to the intrahepatic biliary tree due to the guide-wire. ${ }^{24}$ Despite inconsistency in its treatment due to the lack of case report, most cases of hepatic hematoma following ERCP have been improved by conservative managements including broad-spectrum antibiotics. Percutaneous drainage and embolization may be required for infected hematoma and excessive hematoma, respectively. ${ }^{25}$

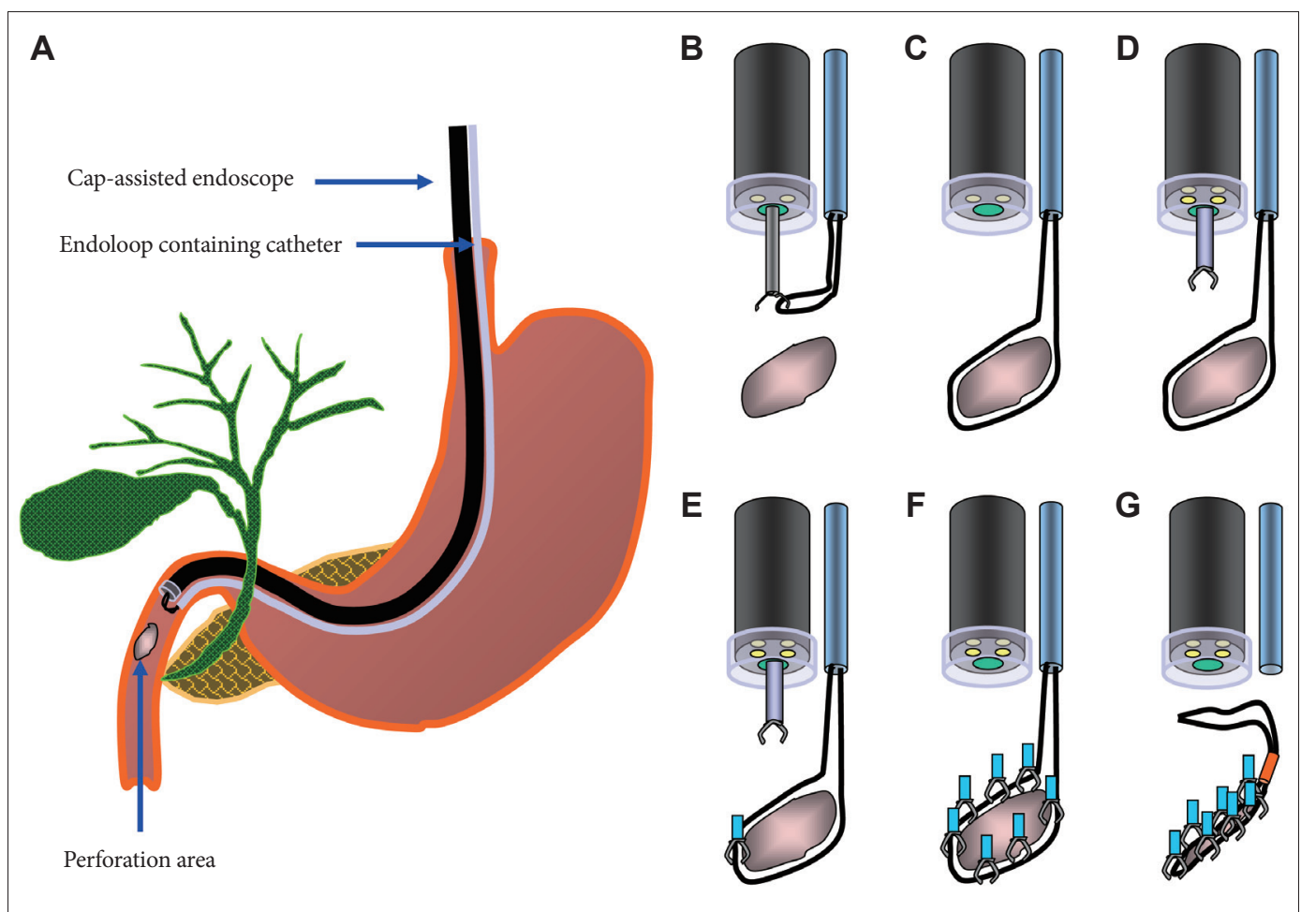

Fig. 6. Illustration of cap-assisted, endoscopic combination therapy with multiple clips and endoloop for type I perforation. (A) Placement of endoscope and endoloop containing catheter around the perforated area. (B) The alligator forceps are opened for detaching the endoloop containing the catheter. (C) The endoloop containing the catheter is properly released around the perforated area. (D) Insertion of the clipping catheter through the working channel. (E) The tip of the endoloop is caught with the clip and clipping is started from the distal margin. (F) Multiple clips are attached with the endoloop to the perforated area and vice versa (a bunch-like clip formation is caught and fixed with the endoloop). (G) The endoloop is tightened and this closes the perforated area. 

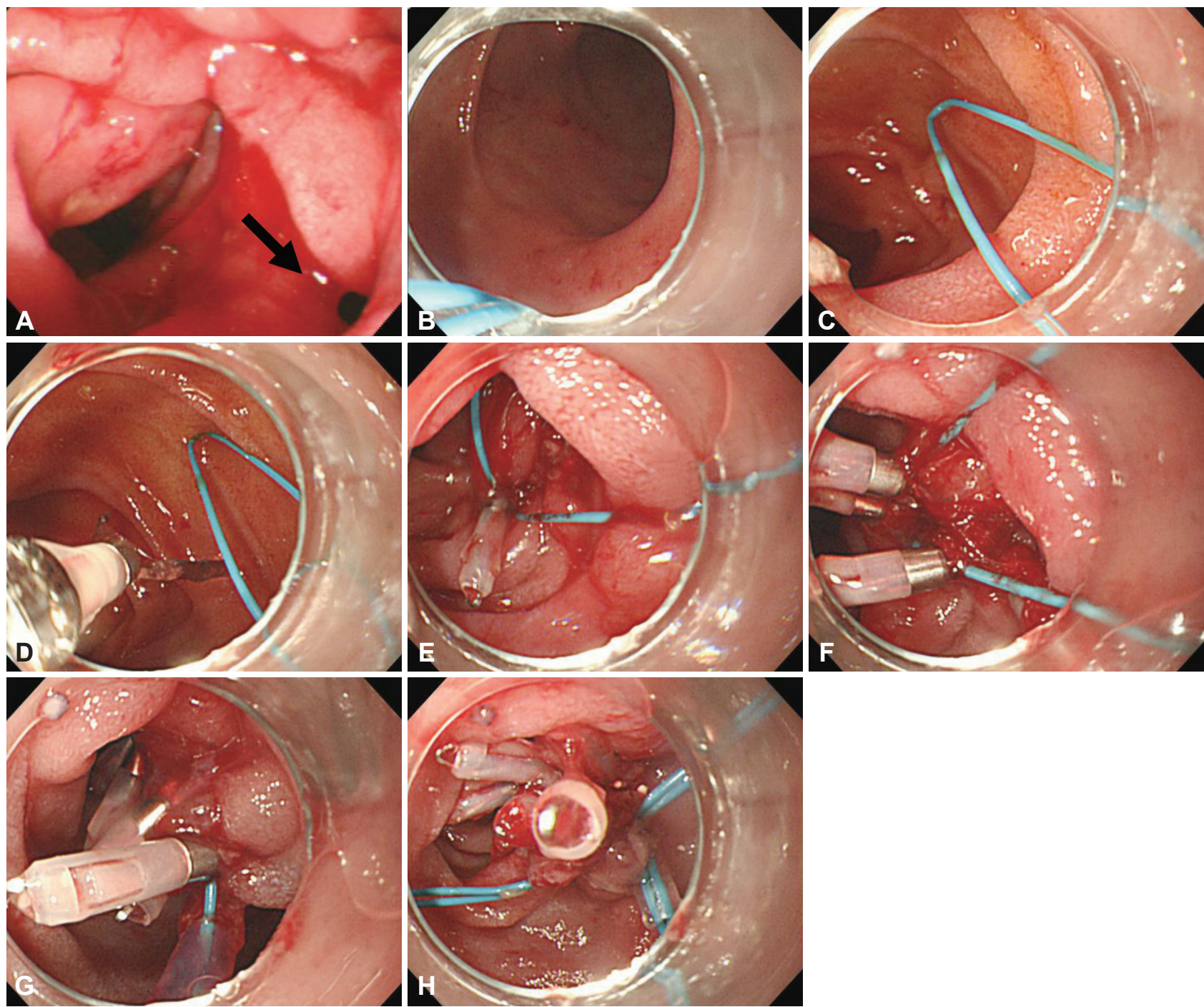

Fig. 7. Endoscopic images of a case with type I perforation (arrow) and successful endoscopic management. (A) A perforation is noted on lateral duodenal wall. (B) Placement of endoscope and endoloop containing catheter around the perforated area. (C) The alligator forceps are opened for detaching the endoloop containing the catheter and the endoloop containing the catheter is properly released around the perforated area. (D, E) The tip of the endoloop is caught with the clip and clipping is started from the distal margin. (F, G) Multiple clips are attached with the endoloop to the perforated area and vice versa (a bunch-like clip formation is caught and fixed with the endoloop). (H) The endoloop is tightened and this closes the perforated area, successfully.

\section{AIR EMBOLISM}

ERCP-induced air embolism is an extremely rare but severe fatal complication, arising from portal venous air embolism. Reported cases were catastrophic since they caused immediate cardiopulmonary collapse upon their occurrence. ERCP-induced portal venous gas is speculated to develop due to a pathophysiologic mechanism where sphincterotomy or high intra-mural pressure of insufflated air disrupts the gastrointestinal or hepatobiliary structure. ${ }^{26-28}$ Sphincterotomy disrupts the duodenal mucosa and creates connection to the veins in the duodenal walls. A large amount of air insufflation during endoscopic examination could pass to the heart via the connection. High intraluminal air pressure during endoscop- ic examination could facilitate the progression of a fatal air embolism. Other reported mechanisms include portal vein puncture due to guide-wire cannulation and erroneous placement of nasobiliary drainage tube to the portal vein. ${ }^{29,30}$ Special care should be taken for possible air embolism, which have been reported by recent wide application of peroral cholangioscopy. ${ }^{31}$

\section{SPLENIC INJURY}

ERCP-induced splenic injury is a very rare condition, presumably arising from the injury to the spleen due to the torsion of the greater curvature, inflicted while inserting a duodenoscope. Severe cases causing splenic rupture may require emergent splenectomy. ${ }^{32-34}$ 


\section{BASKET IMPACTION}

ERCP with mechanical lithotripsy may cause various complications, and one of them is clinically rare basket impaction. The impaction occurs mostly when the basket capturing a bili- ary stone cannot pass through the accompanying distal biliary stricture. ${ }^{35}$ Not only mechanical lithotripsy but also nonlithotriptor basket catheter for removing small stones can create such basket impaction. ${ }^{36}$ Basket impaction may lead to other serious complications because it requires another inva-
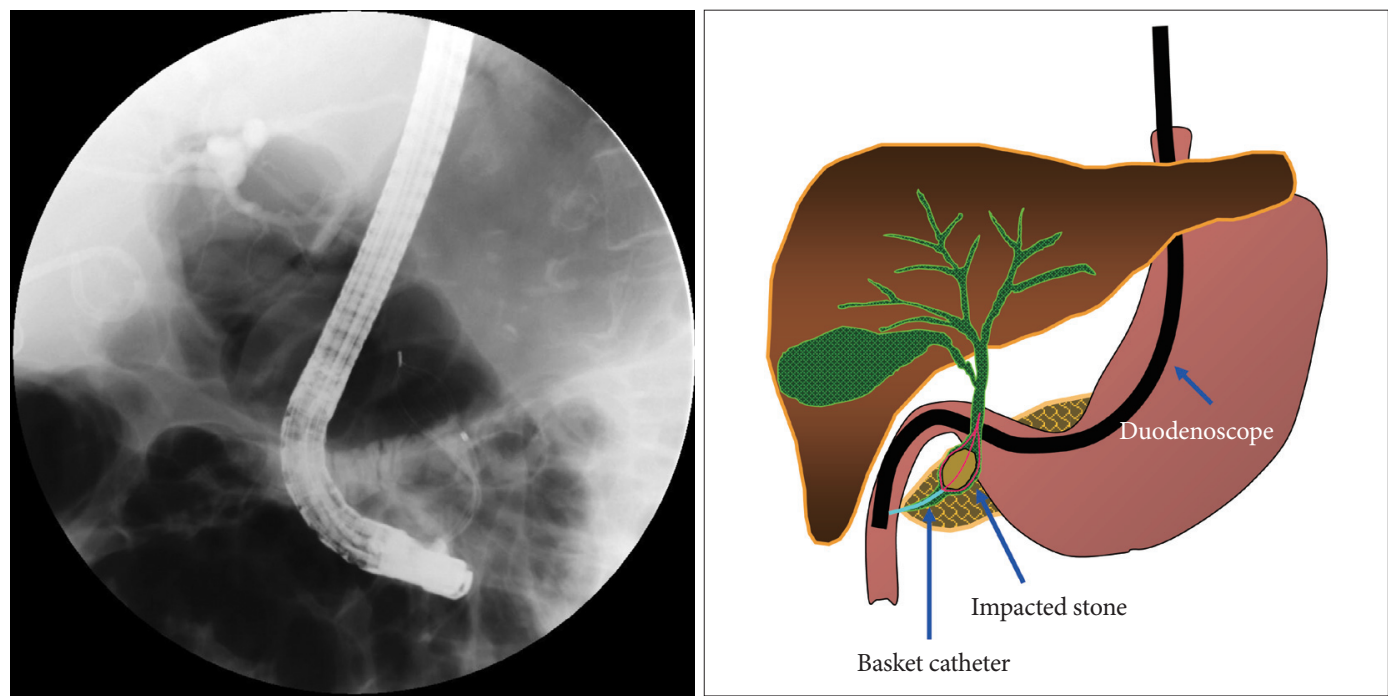

Fig. 8. Basket impaction occurs during removal of stone in case with distal biliary stricture.
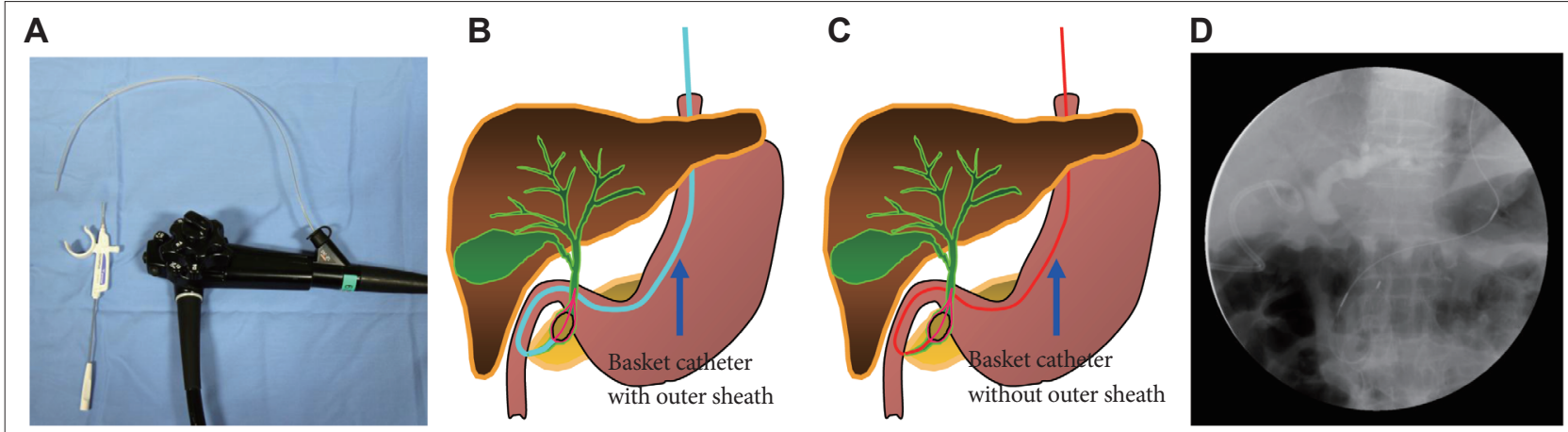

$\mathbf{E}$

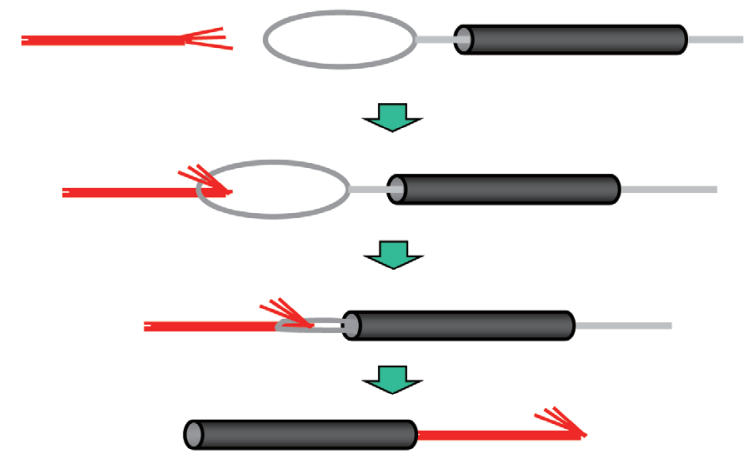

$\mathbf{F}$

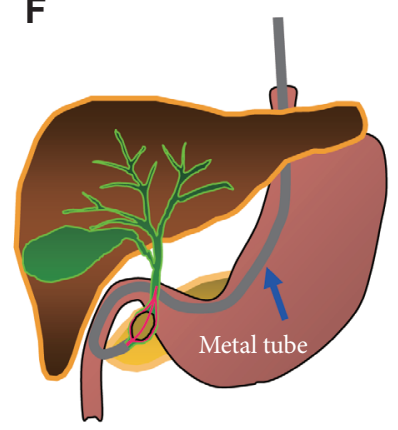

G

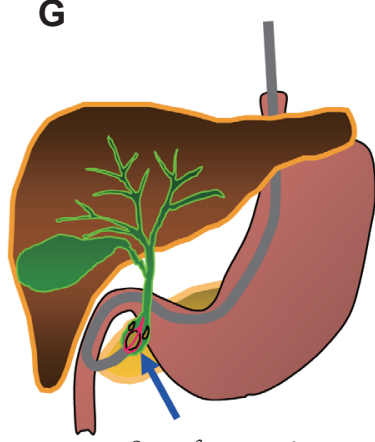

Stone fragmetation by rescue lithotripsy

Fig. 9. Illustration of rescue lithotripsy for basket impaction. (A) Basket catheter is cut near the catheter handle. (B-D) The endoscope and outer sheath of basket catheter are removed. (E) The traction wire is passed through the metal sheath using the snare catheter without outer sheath. (F) The metal sheath is approached at the impacted area over the traction wire. (G) Rescue lithotripsy can crush the impacted stone. 
sive procedure. When unexpected impaction of basket with stone occurs, the basket catheter must be cut near the catheter handle and the endoscope and outer sheath of basket catheter removed. Mechanical lithotripsy catheter has a sufficient length for reaching the impaction area; on the other hand, the length of a normal basket catheter is not enough to reach the impaction area, in which case a snare catheter without outer sheath should be passed through adequately shortened metal sheath first, followed by folding the tip of the traction wire. When the snare catheter is pulled back into the metal sheath again, the traction wire passes through the metal sheath, making the metal sheath to reach the impaction area safely. This method enables tighter fixation, hence crushing of the calculi (Figs. 8, 9). Other useful methods include removal after balloon dilatation of the stricture, extracorporeal shock wave lithotripsy and electrohydrolic lithotripsy using cholangioscopy, or surgical approach when the above methods were failed. ${ }^{37-40}$

\section{RESTENOSIS OR DUODENAL OBSTRUCTION}

Late complication of ERCP with sphincterotomy is papillary restenosis or ampullary restenosis. Although the mechanism is not clear, the restenosis is presumed to occur when the cutting of the sphincter muscle during sphincterotomy is not complete or due to fibrotic reaction at the cutting site. Most of these cases can be successfully treated by repeated sphincterotomy or biliary stenting. ${ }^{41}$ On very rare occasions, some cases develop extensive inflammation and fibrosis causing severe duodenal obstruction that does not respond to a medical treatment. ${ }^{42}$

\section{CONCLUSIONS}

ERCP has facilitated innovative diagnosis and treatment of pancreatobiliary tract diseases, and newer methods are continuously being introduced in this field. Considering the unpredictability of unusual severe complications of ERCP as described earlier, though rare it may be, endoscopists performing ERCP should go through a systematic and thorough training to cope with unexpected complications, should be able to make careful judgment when performing ERCP, and should be well-informed of every possible complications. Endoscopists should also implement all available methods of diagnosis and treatment immediately, without hesitation, upon detection or suspicion of an unpredicted, procedure related unusual complication.

\section{Conflicts of Interest}

The authors have no financial conflicts of interest.

\section{REFERENCES}

1. Aliperti G. Complications related to diagnostic and therapeutic endoscopic retrograde cholangiopancreatography. Gastrointest Endosc Clin N Am 1996;6:379-407.

2. Cotton PB, Lehman G, Vennes J, et al. Endoscopic sphincterotomy complications and their management: an attempt at consensus. Gastrointest Endosc 1991;37:383-393.

3. Freeman ML, Nelson DB, Sherman S, et al. Complications of endoscopic biliary sphincterotomy. N Engl J Med 1996;335:909-918.

4. Kahaleh M, Freeman M. Prevention and management of post-endoscopic retrograde cholangiopancreatography complications. Clin Endosc 2012;45:305-312.

5. Machado NO. Management of duodenal perforation post-endoscopic retrograde cholangiopancreatography. When and whom to operate and what factors determine the outcome? A review article. JOP 2012;13: 18-25.

6. Stapfer M, Selby RR, Stain SC, et al. Management of duodenal perforation after endoscopic retrograde cholangiopancreatography and sphincterotomy. Ann Surg 2000;232:191-198.

7. Enns R, Eloubeidi MA, Mergener K, et al. ERCP-related perforations: risk factors and management. Endoscopy 2002;34:293-298.

8. Howard TJ, Tan T, Lehman GA, et al. Classification and management of perforations complicating endoscopic sphincterotomy. Surgery 1999; 126:658-663.

9. Baron TH, Gostout CJ, Herman L. Hemoclip repair of a sphincterotomy-induced duodenal perforation. Gastrointest Endosc 2000;52:566568.

10. Genzlinger JL, McPhee MS, Fisher JK, Jacob KM, Helzberg JH. Significance of retroperitoneal air after endoscopic retrograde cholangiopancreatography with sphincterotomy. Am J Gastroenterol 1999;94:12671270 .

11. Katsinelos P, Paroutoglou G, Papaziogas B, Beltsis A, Dimiropoulos S, Atmatzidis K. Treatment of a duodenal perforation secondary to an endoscopic sphincterotomy with clips. World J Gastroenterol 2005;11: 6232-6234.

12. Vezakis A, Fragulidis G, Nastos C, Yiallourou A, Polydorou A, Voros D. Closure of a persistent sphincterotomy-related duodenal perforation by placement of a covered self-expandable metallic biliary stent. World J Gastroenterol 2011;17:4539-4541.

13. Park WY, Cho KB, Kim ES, Park KS. A case of ampullary perforation treated with a temporally covered metal stent. Clin Endosc 2012;45: 177-180.

14. Nam HS, Kim GH, Kim DU, et al. A case of duodenal perforation caused by biliary plastic stent treated with approximation using endoclip and detachable snare. Korean J Gastroenterol 2011;57:129-133.

15. Seibert DG. Use of an endoscopic clipping device to repair a duodenal perforation. Endoscopy 2003;35:189.

16. Sebastian S, Byrne AT, Torreggiani WC, Buckley M. Endoscopic closure of iatrogenic duodenal perforation during endoscopic ultrasound. Endoscopy 2004;36:245.

17. Lee TH, Bang BW, Jeong JI, et al. Primary endoscopic approximation suture under cap-assisted endoscopy of an ERCP-induced duodenal perforation. World J Gastroenterol 2010;16:2305-2310.

18. Endo M, Inomata M, Terui T, et al. New endoscopic technique to close large mucosal defects after endoscopic mucosal resection in patients with gastric mucosal tumors. Dig Endosc 2004;16:372-375.

19. Matsuda T, Fujii T, Emura F, et al. Complete closure of a large defect after EMR of a lateral spreading colorectal tumor when using a twochannel colonoscope. Gastrointest Endosc 2004;60:836-838.

20. Sanders MK, Malick J, Fasanella KE, Watson AR. Endoscopic closure of iatrogenic duodenal perforation during EUS in a patient with un- 
usual anatomy. Gastrointest Endosc 2008;68:802-804.

21. Kim DH, Kwon CI, Chung JG, et al. Endoscopic hemostasis with multiple hemoclips and an endoloop for uncontrolled peptic ulcer bleeding. Endoscopy 2011;43 Suppl 2 UCTN:E3-E4.

22. Schepers NJ, van Buuren HR. Pneumothorax following ERCP: report of four cases and review of the literature. Dig Dis Sci 2012;57:1990-1995.

23. Al-Ashaal YI, Hefny AF, Safi F, Abu-Zidan FM. Tension pneumothorax complicating endoscopic retrograde cholangiopancreatography: case report and systematic literature review. Asian J Surg 2011;34:46-49.

24. Ortega Deballon P, Fernández Lobato R, García Septiem J, Nieves Vázquez MA, Martínez Santos C, Moreno Azcoita M. Liver hematoma following endoscopic retrograde cholangiopancreatography (ERCP). Surg Endosc 2000;14:767.

25. Del Pozo D, Moral I, Poves E, Sanz C, Martín M. Subcapsular hepatic hematoma following ERCP: case report and review. Endoscopy 2011; 43 Suppl 2 UCTN:E164-E165.

26. Nayagam J, Ho KM, Liang J. Fatal systemic air embolism during endoscopic retrograde cholangio-pancreatography. Anaesth Intensive Care 2004;32:260-264.

27. Kennedy C, Larvin M, Linsell J. Fatal hepatic air embolism following ERCP. Gastrointest Endosc 1997;45:187-188.

28. Cha ST, Kwon CI, Seon HG, et al. Fatal biliary-systemic air embolism during endoscopic retrograde cholangiopancreatography: a case with multifocal liver abscesses and choledochoduodenostomy. Yonsei Med J 2010;51:287-290.

29. Kalaitzakis E, Stern N, Sturgess R. Portal vein cannulation: an uncommon complication of endoscopic retrograde cholangiopancreatography. World J Gastroenterol 2011;17:5131-5132.

30. Furuzono M, Hirata N, Saitou J, Nakaji S. A rare complication during ERCP and sphincterotomy: placement of an endoscopic nasobiliary drainage tube in the portal vein. Gastrointest Endosc 2009;70:588-590.

31. Efthymiou M, Raftopoulos S, Antonio Chirinos J, May GR. Air embolism complicated by left hemiparesis after direct cholangioscopy with an intraductal balloon anchoring system. Gastrointest Endosc 2012;75: 221-223.

32. Zyromski NJ, Camp CM. Splenic injury: a rare complication of endoscopic retrograde cholangiopancreatography. Am Surg 2004;70:737-739.

33. Deist TJ, Freytag A. Splenic rupture after ERCP. Z Gastroenterol 2003; 41:579-582.

34. Lo AY, Washington M, Fischer MG. Splenic trauma following endoscopic retrograde cholangiopancreatography (ERCP). Surg Endosc 1994; 8:692-693.

35. Payne WG, Norman JG, Pinkas H. Endoscopic basket impaction. Am Surg 1995;61:464-467.

36. Kim WH, Kwon CI, Han JH. Rescue lithotripsy to treat basket impaction. Endoscopy 2012;44 Suppl 2 UCTN:E209-E210.

37. Katsinelos P, Fasoulas K, Beltsis A, et al. Large-balloon dilation of the biliary orifice for the management of basket impaction: a case series of 6 patients. Gastrointest Endosc 2011;73:1298-1301.

38. Kwon JH, Lee JK, Lee JH, Lee YS. Percutaneous transhepatic release of an impacted lithotripter basket and its fractured traction wire using a goose-neck snare: a case report. Korean J Radiol 2011;12:247-251.

39. Attila T, May GR, Kortan P. Nonsurgical management of an impacted mechanical lithotriptor with fractured traction wires: endoscopic intracorporeal electrohydraulic shock wave lithotripsy followed by extraendoscopic mechanical lithotripsy. Can J Gastroenterol 2008;22:699702.

40. Fukino N, Oida T, Kawasaki A, et al. Impaction of a lithotripsy basket during endoscopic lithotomy of a common bile duct stone. World J Gastroenterol 2010;16:2832-2834.

41. Elmi F, Silverman WB. Long-term biliary endoscopic sphincterotomy restenosis: incidence, endoscopic management, and complications of retreatment. Dig Dis Sci 2010;55:2102-2107.

42. Lim JU, Joo KR, Park JJ, Shin HP, Cha JM, Lee JI. Duodenal obstruction following papillary stenosis: a rare complication after endoscopic sphincterotomy. Endoscopy 2010;42 Suppl 2:E342-E343. 